\title{
Research on Chinese-Language film in the Context of Globalization
}

\author{
Jing $\mathrm{Yi}^{1, \mathrm{a}}$ and Jianxun $\mathrm{Wu}^{2, \mathrm{~b}}$ \\ ${ }^{1}$ Beijing Film Academy, China \\ ${ }^{2}$ Beijing Film Academy, China \\ ayijing_1994@126.com, 'bujianxunbfa@outlook.com
}

Keywords: Film Globalization; Chinese-language film; Film industry

\begin{abstract}
Chinese-language films have experienced the whole - divide - cooperation - integration process in the past 68 years has experienced. In recent years, mainland China, Hong Kong, Macao, Taiwan and overseas Chinese new generation of directors have realized the century cultural integration of Chinese-language film across different nation and region. This article critically reviewed the development of Chinese-language film on the basis of national film and Chinese film, trying to construct an analytical framework of Chinese-language films in the era of globalization, and exploring the Chinese movie industry how to realize the new development in the new pattern culture of globalization.
\end{abstract}

\section{Introduction}

The Chinese-language film refers to the film produced by the mainland China, including Hong Kong, Macao and overseas Chinese of east Asia and southeast Asia. Over the past century, the number of Chinese films has been over a million, including Chinese, Cantonese, Hakka, Hujian (Taiwanese), tidal language, dialect and a small number of English.

The profound social background, cultural roots and industrial connections all promote the coming out and acceptance of the concept of Chinese-language film. The shared cultural traditions such as the language, literature and food are rooted in the same culture- the long lasting traditional Chinese culture and the consistent film traditions-Shanghai film traditions before 1949. There exist inner centripetal requirements and common pursuit of the behaviors of film production and consumption in mainland China, Hong Kong, Taiwan and even other Chinese-speaking regions such as Singapore and Malaysia. This concept has a strong integration and a wide range of incisiveness, whether it is national, cross-regional, multinational or international, all can be integrated into Chinese films. The concept of Chinese-language film specifically defines the research subjects and versions. Whereas, in fact, the practice of Chinese film is still in development, just as the fact that the critical connotation of the concept of a Chinese-language film industry remains to be further expounded. In a word, the research on Chinese-language film in the context of globalization has only just started.

Since 1949, the political separation of the mainland, Hong Kong and Taiwan has obscured the domestic identity of Chinese films. In daily use, Chinese films mainly refer to the Chinese films before 1949 and mainland films after 1949.The existing academic works in the name of "Chinese film", basically refer to the mainland Chinese films as the main object, or according to the specific needs, selectively add some individual relevant Hong Kong and Taiwan films. For nearly 30 years after 1949, mainland China, Hong Kong, Taiwan's film industry is basically maintained separate operation, an independent development pattern, sustained by their respective independent film system.

But if put the differences between the politics, film system, the mode of operation, etc, aside, due to the consistent of racial and cultural homogeneity, under the common ethics thoughts and the influence of Confucianism, the chivalrous culture, the profound traditional agricultural culture and local consciousness infiltration, mainland China, Hong Kong and Taiwan even the overseas Chinese-language films were actually share the same or similar spiritual kernel and cultural 
connotation.

\section{What is the Basic Research Problem of Film Globalization}

Before the 1980s, there were few foreign studies of Chinese films. With the rapid advance of China's reform and opening up, especially the first Hollywood movies in the form of separate accounts introduced to China in 1994, The Fugitive (1993), and the enormous success of Titanic(1998) (USD 0.6 billion, which accounted for a third of the country's total ), more and more researchers begin to notice the Chinese film market. And before 2002, mainly focused on the fundamental issues of film globalization and the globalization of Hollywood films.

After the British scholar Giddens (1990) put forward by the the new concept of "globalization", people realized that movies were part of the pioneers of globalization. Globalization, which is the capital, goods, or the transnational flow of labor and symbol or information (Hirst and Thompson, 1996), is caused by the expansion of the correspondence relationship between global, deeply and quickly, thus forming the compression of the world and further perception of the world as a whole the strengthening of the consciousness.

As for the impact of globalization on films, the first observation of scholars is that the feature is also relatively large because of high production costs. (Vogel,1998; Horner, 2000; Eliashberg et al., 2006) The second observation is that there is uncertainty about film demand. When the market size increases, the uncertainty of film demand increases correspondingly, and the returns on film investments will also increase accordingly (Sawhney and Elishberg, 1996; Walls, 2005) . Scholars generally agree that globalization and transnational capitalism can affect the domestic society and individuals in these societies. However, when it comes to the interaction between globalization and culture, scholars often fail to gain consensus. Many scholars' research attempts to answer and explain how transnational capitalism affects culture, and whether its influence is a single direction or multi-direction? Will American cultural products actually dissolve the local culture? Has globalization produced more subcultures?

After 2002, with China's accession to the WTO, overseas scholars gradually made their research into Chinese films. Kaylin Dillon (2015) believes that globalization plays an important role in the development of Hollywood films in China. It was believed that globalization has reshaped the film industry, with Avatar(2009) taking in \$194 million in China, attracting many overseas film companies to the Chinese film industry.

Since the "Chinese New Movie Campaign" launched in early 1980, the introduction of the viewpoints and versions from western film researches has brought positive effects on Chinese-language film researches. However, some Chinese critics and scholars, in order to prove the legality of their own theories, would first of all find the supporting points from western theories instead of thinking over whether the western theories fit the reality of Chinese cultural background, which is one of the crucial problems should be laid great attention to when conducting cross-cultural researches and criticisms.

Recently, the progress of the researches on Chinese-language film is gradually showing two corresponding trends: the macro and the micro developing trend. The author holds that the comprehensive and microscopic studies supplement each other. Only with the combination and integration of the two, can we truly achieve a complete and relatively objective research on the history of Chinese-language film and have a combined understanding of the modern attitude of western culture and the recognization of local culture. In order to avoid that the film would be substituted by history, and to avoid sinking into the sole study of culture, this research on Chinese-language film with the influence of globalization should always sticks to the focus of film itself and carries out studies on film characteristics - the basic audio-visual language, the form and the nature of movies. The author of this paper mainly hopes to raise that how the Chinese movie directors maintain a clear attitude and hold a strong agreement with traditional Chinese culture while facing the strong impact of western modernization and the rapid development of modern 
society.

\section{The Complexity Development Path of "National Fable"}

The Chinese-language film originally in Shanghai as the center, east film plate broken after 1949, then the north formed the northern film plate, besides, some of the film elements have come to the south with other factors to form Hong Kong and Taiwan films. After the reform and opening up, the north film plate breakage, identified the part of the Western Movie Group based Xi'an as western films plate, along with the emergence of the fifth generation of Chinese directors, such as Zhang Yimou's "Red sorghum," "Raise the Red Lantern", Chen Kaige's " Yellow Earth" and so on.

Since the 1980s, as the diplomatic situation in the mainland, Hong Kong and Taiwan has changed, the film exchanges and cooperation began to sprout. After the policy of reform and opening up the mainland, the 1982 British negotiations have set the agenda for the handover of Hong Kong in 1997.In the wake of the "martial law", Taiwan has opened the ban of the party and the press, then gradually lifted restrictions on operas, movies, music, painting and other aspects. We can see the tendency of "integration", which undoubtedly exacerbates the complexity of Chinese film identity. The Chinese film center moved to Beijing in the 90s, and Feng Xiaogang "The Dream Factory" and Jiang Wen" In the Heat of the Sun" and so on as representative's new style northerly style appeared. Hong Kong filmmakers came to the north, and put action, Kongfu and comedy together, form like "New Dragon Gate Inn", " Once Upon a Time in China III" those new form of win-win for box office and public praise. The Chinese-language film from collage across modules to further integration of across modules, blends together both the film technology and art, was reshaping Chinese film or Chinese style.

In general, the Chinese film as a whole, reconstruct the historical authenticity 'original', on the overall cultural implications to remold Chinese artistic image. It was been brought to the whole world, but not as a result of these image gives them a so-called 'folk/political wonders of the east' or an Oriental 'otherness' image, which is made by Chinese artists from a new perspective of modern remake of a real, unique oriental aesthetic charm of 'China/Chinese image'. The mould of the glory of the historic culture, its key point is that these works effectively to give the 'China' and "China/Chinese image" to the body of the local ethnic culture, which embodies the healthy development of the main flow of Chinese film industry.

However, there are also some unique examples that we had to face the complexity of "national fable". While some national cinema went into the famous international film festival and won the title, originally should be playing the international context of cultural dialogue be arbitrary type "abstraction", placed them in the "western the other" space from an imaginary western perspective, and the national film unconsciously begin to self deprecating or self dwarf. This is also because Chinese films in the context of globalization cannot be detached, and have begun to be involved in the global division of labor. Thus, the latest film is being created. The new generation of directors from the sixth generation has not been able to erase the "pure" cultural imagination of "China" in the same way as the fifth generation " art movie".

\section{The Modern Choice of " Imagined Communities"}

In the age of globalization, the film actually bears the civilizing function of shaping the national imagination and maintaining the " imagined communities ". Chinese blockbusters have put forward a way to watch Chinese, they are both the concrete practice of the economic globalization in the field of film industry, and as a popular cultural product to provide for the imagination of China.

Chinese-language film arguably responded to the new wave of Chinese film under the background of globalization, trying to build an everything -- include mainland China, Hong Kong, Taiwan and even the whole of the overseas Chinese, the Chinese film research Angle of view, while the flaw of the concept itself is also obvious. Globalization has not only contributed to the mainland, Hong Kong and Taiwan movies (including overseas Chinese film) and the relation between 
integration, at the same time as a whole or combination, those regions' films industry also maintained the close ties between other countries/regions under the influence of globalization and, the concept of Chinese-language film does not seem to fully respond to this part of the reality.

In the context of globalization, the Asian film with the rapid development of Chinese movie industry has become an influential force in the world film pattern: the Chinese film market has become the world's second-largest market after the United States. Over the past five years, China's film industry leads the cultural industry into the golden age of progress. The Chinese movie box office maintained a $35.6 \%$ average annual growth rate, mainland Chinese film total box office of USD 6.95 billion in 2016, and the total number of screens has reached 45,000, surpassing the United States as the world's largest.

The global co-production has also become an important part of China's film industry in recent years. In 2016, there were 89 co-production films was released in mainland China. The co-productions cover 17 countries and regions. Among them, the co-production films of mainland and Hong Kong were 54, with China and the United States were 10, and the mainland with Taiwan was 8 , which accounted for $81 \%$ of the total number of co-productions.In recent years, the number of Chinese mainland co-productions, box office, cooperative countries and regions have increased substantially. (Table 1)

Table 1:2011-2016 co-production, co-production, and box office

\begin{tabular}{|l|l|l|l|l|l|l|}
\hline Year & 2011 & 2012 & 2013 & 2014 & 2015 & 2016 \\
\hline Co-productions & 73 & 66 & 55 & 77 & 94 & 96 \\
\hline Cooperation with Hong Kong & - & 39 & 34 & 46 & 48 & 54 \\
\hline Countries and regions involved & - & 7 & 7 & 12 & 13 & 17 \\
\hline Accounts for the annual box office share & $11.1 \%$ & $8.9 \%$ & $15.2 \%$ & $21.6 \%$ & $24.3 \%$ & $32.5 \%$ \\
\hline
\end{tabular}

The new global cultural landscape has brought us to this group of keywords: 'the implementation process' and 'cross-boundary dialogue'. As a formal WTO member, China must fulfill existing conventions and WTO rules. At 2018, China's commitment to the film "annex 9"of PROTOCOL ON THE ACCESSION OF THE PEOPLE'S REPUBLIC OF CHINA and the Memorandum of Understanding between China and the United States on Solving WTO Film Related Issues will soon expire. In other words, the Chinese film market will further open. The 'transition' was over, so the cultural commitment has to cash in the field of distribution. China's integration into globalization is deepening, and the massive entry of Hollywood as the main body of transnational capital has brought more subtle and pressing challenge. The "imagined communities" have entered the "game time" of challenges and opportunities.

\section{Conclusion}

To sum up, globalization has had a profound impact on many aspects of the Chinese-language film. Globalization has not only brought Chinese films to the intercontinental level, but also integrated transnational factors into Chinese films, resulting in the complicated situation of Chinese films industry. Film and Chinese-language films are not only the products of globalization and modernity, but also the significant "push hand" of cultural globalization and modernity. In the era of globalization, Chinese directors were encountering a common problem: how to convey the contradictory confusion between western modernity and the traditional Chinese cultural identity?

Globalization has further brought about the transnational vision of Chinese film research. Under the background of globalization of Chinese film and Chinese film studies of transnational, Chinese films is required to construct their own identity in the field of worldwide film, or embodied a kind of intersubjectivity. In the comparisons of films production, aesthetics, culture and industry, the modern and traditional differences, integrative research in the context of the overall, comparative research and impact study, need to think about the current situation and future of the Chinese film 
be at the local, regional and world level of various factors of conflict and fusion, so as to explore the Chinese film culture facing the world as a whole.

\section{Acknowledgement}

In this paper, the research was sponsored by the National Social Science Fund of China (Project No. 16ZD04).

\section{References}

[1] Giddens A. The consequences of modernity[J]. 1990, 13(3):325-327.

[2] Paul Hirst, Grahame Thompson. The problem of 'globalization": international economic relations, national ecnomic management and the formation of trading blocs[J]. Economy \& Society, 1992, 21(4):357-396.

[3] Vogel H L. Entertainment industry economics: a guide for financial analysis. [M]. Cambridge University Press, 2007.

[4] Horner J. Creative Industries: Contracts between Art and Commerce[J]. Journal of Economic Issues, 2000, 46(4):10.

[5] Elberse A, Eliashberg J. Demand and Supply Dynamics for Sequentially Released Products in International Markets: The Case of Motion Pictures[M]. INFORMS, 2003.

[6] Sawhney M S, Eliashberg J. A Parsimonious Model for Forecasting Gross Box-Office Revenues of Motion Pictures[M]. INFORMS, 1996.

[7] W.D. Walls. Modelling heavy tails and skewness in film returns[J]. Applied Financial Economics, 2005, 15(17):1181-1188.

[8] Dillon K. Hollywood in China: The Chinese Reception of 'Titanic' as a Case Study[J]. 2015.

[9] Zhang Yiwu. Transformation of globalization and Chinese films [M]. China Renmin University Press, 2006.

[10]Dai Jinhua. Landscape in fog: Chinese film culture 1978-1998[M]. Peking University press, 2006. 